\title{
Reduced incidence of tuberculosis by prophylactic chemotherapy in subjects showing strong reactions to tuberculin testing
}

\author{
L P ORMEROD
}

Blackburn Royal Infirmary, Blackburn, England

SUMMARY The introduction of chemoprophylaxis with rifampicin and isoniazid in 1981 significantly reduced the incidence of tuberculosis. Between 1978 and 1981 children accounted for 136 of 642 notified cases, and this was reduced to 55 of 418 between 1982 and 1986. This effect was most obvious among children from the Indian subcontinent who comprised $80 \cdot 2 \%$ of the children treated. The incidence among white children was not affected. Few side effects occurred and only two of $339(0.6 \%)$ later developed clinical tuberculosis. Chemoprophylaxis plays an important part in the management of tuberculosis in a district with a high incidence of the disease.

The Blackburn local government area had the highest incidence of tuberculosis in England and Wales in $1970,{ }^{1}$ the fourth highest between 1978 and $1979,{ }^{2}$ and the fifth highest in $1983 .^{3}$ Immigrants from the Indian subcontinent accounted for 70 to $80 \%$ of notifications for these years. Nearly $20 \%$ of all notifications in the health district for 1978-80 were of children 0 to 15 years old, $89 \%$ of them being from the Indian subcontinent despite an active neonatal vaccination programme with Bacillus Calmette Guerin (BCG), with a $92 \%$ average acceptance rate. In 1981 the paediatric notifications rose to 55 of $164(33.5 \%)$ of all notifications (table 1).

Because of the continuing high incidence of tuberculosis in the general population, and in children in particular, routine prophylactic chemotherapy was introduced in November 1981 throughout the district. Secondary chemo-

Table 1 Notifications of cases of tuberculosis 1978-81

\begin{tabular}{|c|c|c|c|c|}
\hline & 1978 & 1979 & 1980 & 1981 \\
\hline Total No of notifications & $130^{*}$ & $186^{*}$ & $162^{*}$ & 164 \\
\hline $\begin{array}{l}\text { No of children from } \\
\text { Indian subcontinent }\end{array}$ & 14 & 29 & 29 & 37 \\
\hline No of white children & 4 & 3 & 2 & 18 \\
\hline Total No of children & 18 & 32 & 31 & 55 \\
\hline $\begin{array}{l}\text { Total No of children as \% } \\
\text { of total No of notifications }\end{array}$ & $13 \cdot 8$ & $17 \cdot 2$ & $19 \cdot 1$ & $33 \cdot 5$ \\
\hline
\end{tabular}

${ }^{*}$ Figures underestimate due to undernotification. prophylaxis - that is, after evidence of exposurewas not used routinely before 1981 , although primary chemoprophylaxis with isoniazid $5 \mathrm{mg} / \mathrm{kg}$ was given to the babies of women diagnosed as having sputum smear or culture positive pulmonary tuberculosis in the last trimester of pregnancy until active immunisation with isoniazid resistant BCG was effective.

The Joint Tuberculosis Committee of the British Thoracic and Tuberculosis Association suggested giving isoniazid $5 \mathrm{mg} / \mathrm{kg}$ alone, or with additional ethambutol $15 \mathrm{mg} / \mathrm{kg}$, to children whose skin tests were positive for tuberculin. ${ }^{4}$ The evidence in favour of using isoniazid alone comes from several studies of contacts, ${ }^{5-7}$ and of patients with fibrotic, inactive lesions. ${ }^{8}$ The usual regimens of isoniazid were $5 \mathrm{mg} / \mathrm{kg}$ for $26-52$ weeks, 52 weeks being more effective than 26 weeks for inactive pulmonary lesions. ${ }^{8}$ Isoniazid has few side effects and some of those reported may be attributed to the sporadic occurrence of hepatitis in the community. Thompson reported hepatitis in $0.5 \%$ receiving the drug and in $0 \cdot 1 \%$ taking placebo. ${ }^{8}$ In the United States Public Health Service trials in contacts isoniazid was stopped because of side effects in $1.9 \%$, compared with $1.5 \%$ for those taking placebo alone. ${ }^{9}$ Brunner also showed that the incidence of hepatitis in patients taking isoniazid was rare. ${ }^{10}$ Some authors ${ }^{11}$ have considered the risk of emergence of organisms resistant to isoniazid to be unfounded, but Gryzbowski et at ${ }^{6}$ showed that of those given isoniazid 
chemoprophylaxis who subsequently developed active disease, $16 \%$ had organisms resistant to the drug. They were, however, unable to show whether this resistance had been present initially or whether it was due to treatment with the single drug alone.

The regimen chosen initially was isoniazid 10 $\mathrm{mg} / \mathrm{kg}$ and rifampicin $10 \mathrm{mg} / \mathrm{kg}$, with pyridoxine 10 $\mathrm{mg}$ daily for nine months. Rifampicin was included to reduce the length of treatment, and because of the high incidence $(6 \%)$ locally of primary isoniazid resistance seen in the index cases from the Indian subcontinent. ${ }^{12}$ The dosage of rifampicin $(10 \mathrm{mg} / \mathrm{kg})$ was chosen because this was at the lower end of the dose range of $10-20 \mathrm{mg} / \mathrm{kg}$ recommended for children, and older children of $30 \mathrm{~kg}$ and over would not receive a dose above the maximum recommended of $600 \mathrm{mg} /$ day. Because of the high incidence of the disease in children in 1981 when the regimen was introduced, the duration of the initial course was deliberately made longer than we intended to use later (six months), to make as large an impact as possible on the incidence in children.

\section{Methods}

A district contact clinic was set up in November 1981 and held weekly. All contacts of index cases of tuberculosis, children who showed a positive reaction to tuberculin skin testing at school, and all new immigrants were referred for $x$-ray picture, physical examination, and tuberculin test (Tine) reading. The criteria set out for chemoprophylaxis in 1981 at the beginning of the scheme have remained the same. Chemoprophylaxis was advised in children from 0 to 15 years if they had a positive tuberculin test of grade 2, 3, or 4 with no history of BCG vaccination; a positive tuberculin test grade of 3 or 4 with a history of BCG vaccination; had recently become positive to a tuberculin test; or if they were new immigrants with grade 3 or 4 positive tuberculin tests, or had a 'healed' lesion shown on $x$-ray picture.

These criteria are similar to those subsequently recommended by the Joint Tuberculosis Committee in $1983,{ }^{13}$ and in an editorial in the Lancet $^{14}$ on prevention of tuberculosis with isoniazid. The Joint Tuberculosis Committee recommended isoniazid 10 $\mathrm{mg} / \mathrm{kg}$ for six to 12 months.

After initial assessment by the chest physician children who fulfilled the above criteria were recommended to have chemoprophylaxis. From November 1981 to December 1983 inclusive a nine month regimen of isoniazid $10 \mathrm{mg} / \mathrm{kg}$, rifampicin 10 $\mathrm{mg} / \mathrm{kg}$, and pyridoxine $10 \mathrm{mg}$, all taken once daily, was given. From January 1984 to December 1986 a six month regimen with identical doses was given.
Compliance was monitored by monthly visits from the health visitor who also checked with the chemists and general practitioners that regular prescriptions were being obtained. Children were seen every three months at the clinic during the course of treatment and had an $x$-ray picture taken before chemoprophylaxis was stopped. From November 1981 to December 1984 children were checked six and 15 months after drug treatment was stopped. From January 1985 children were discharged after completing the six months' course.

The case notes of all children notified as having tuberculosis between 1978 and 1980 were reviewed. These cases were true notifications with evidence of primary tuberculosis or mediastinal tuberculous lymphadenopathy on chest $x$-ray picture, or histological evidence of non-pulmonary tuberculosis. No child had been notified for chemoprophylaxis rather than treatment. There has been no change in the consultant staff in chest medicine or paediatrics since 1981, and they have maintained the same clinical criteria for the diagnosis of tuberculosis throughout.

\section{Results}

Table 2 shows the number of children given chemoprophylaxis, the duration of treatment, and the ethnic distribution. Drug reactions were uncommon. Four children of $339(1.2 \%)$ had their chemoprophylaxis changed to isoniazid $10 \mathrm{mg} / \mathrm{kg}$ and ethambutol $15 \mathrm{mg} / \mathrm{kg}$ because of vomiting. No case of rash, obvious liver function abnormality, or peripheral neuropathy was seen. Only two children of $339(0 \cdot 6 \%)$ who received chemoprophylaxis subsequently developed clinical tuberculosis (one each in 1985 and 1986), and there were reservations about compliance in these cases. Four children whose parents refused to give them chemoprophylaxis when so advised developed clinical tuberculosis within 12 months of that advice.

Table 3 shows notifications for 1978 to 1986. There are significant differences between the total

Table 2 Details of chemotherapy regimens

\begin{tabular}{llc}
\hline Year of study & $\begin{array}{l}\text { Duration of treatment } \\
\text { regimen (months) }\end{array}$ & $\begin{array}{l}\text { No of } \\
\text { patients }\end{array}$ \\
\hline November 1981- & & \\
December 1982 & 9 & $118^{*}$ \\
1983 & 9 & $102^{*}$ \\
1984 & 6 & $43^{*}$ \\
1985 & 6 & 31 \\
1986 & 6 & 45 \\
\hline
\end{tabular}

*Followed up for 15 months after treatment. 
Table 3 Notifications of children with tuberculosis 1978-1986

\begin{tabular}{|c|c|c|c|c|c|c|c|c|c|}
\hline & 1978 & 1979 & 1980 & 1981 & 1982 & 1983 & 1984 & 1985 & 1986 \\
\hline $\begin{array}{l}\text { No of children notified } \\
\text { (Indian subcontinent) } \\
\% \text { Of total notifications }\end{array}$ & 14 & 29 & 29 & 37 & 20 & 7 & 4 & 6 & 2 \\
\hline $\begin{array}{l}\text { (Indian subcontinent) } \\
\text { No of children notified }\end{array}$ & $17 \cdot 1$ & $22 \cdot 5$ & $23 \cdot 6$ & $36 \cdot 6$ & $27 \cdot 4$ & $11 \cdot 1$ & $10 \cdot 5$ & $14 \cdot 6$ & $4 \cdot 1$ \\
\hline & 4 & 3 & 2 & 18 & 4 & 5 & 6 & 0 & 1 \\
\hline $\begin{array}{l}\text { (white) } \\
\text { Total No of children }\end{array}$ & $8 \cdot 3$ & $5 \cdot 3$ & $5 \cdot 1$ & $28 \cdot 6$ & $12 \cdot 1$ & $15 \cdot 2$ & $17 \cdot 6$ & 0 & $3 \cdot 6$ \\
\hline $\begin{array}{l}\text { notified } \\
\% \text { Of total No of cases }\end{array}$ & 18 & 32 & 31 & 55 & 24 & 12 & 10 & 6 & 3 \\
\hline
\end{tabular}

notifications from 1978 to 1981 compared with those for 1982-86 $\left(\chi^{2}=11 \cdot 04, p<0 \cdot 001\right)$ and those from 1978-81 compared with those from 1984-86 $\left(\chi^{2}=16 \cdot 75, p<0 \cdot 001\right)$. Differences in notifications of cases of tuberculosis among children from the Indian subcontinent are also significant when the same time periods are compared $\left(\chi^{2}=10.41\right.$, $\mathrm{p}<0.01$, and $\chi^{2}=14.42, \mathrm{p}<0.001$, respectively). There were no significant differences in the number of notifications of white children.

\section{Discussion}

There can be no doubt that the pattern of tuberculosis in the health district has been appreciably changed by the introduction of prophylactic chemotherapy. To allow for the considerable fall in notifications generally, the paediatric notifications were expressed as a percentage of their ethnic group and of the total for that year, to see if the ratio as well as the absolute numbers had fallen. It may be that the inclusion of the 1981 figures distorts the analysis because chemoprophylaxis was introduced during that year, but this was only in the last two months of the year and so was unlikely to have had any effect on the pattern of disease in that year. Furthermore, removal of the 1981 figures may have a negative bias on the results, as we know that the 1981 figures reflect the true pattern of disease, whereas the figures for 1978-80 are known to underestimate the incidence of the disease among children (table 1).

We thought that the introduction of chemoprophylaxis would have a much greater effect on the incidence of tuberculosis among children from the Indian subcontinent for the following reasons: (i) Immigrants formed $67.5 \%$ of the total and $89 \%$ of the paediatric cases in 1978-80 (table 1). (ii) A higher percentage of white index cases had pulmonary disease with positive sputum culture, so giving a higher incidence of clinical primary infection at first attendance, with less chance to intervene to prevent disease. (iii) In contacts from the Indian subcontinent group, a smaller percentage of those found subsequently to have clinical tuberculosis were found at the initial screening, so giving an increased chance of cure by chemoprophylaxis. ${ }^{15}$ (iv) The estimated annual notification rate per 100000 for the under 15 age group in the white ethnic group was $3 \cdot 6$, but for the Indian subcontinent group born in the United Kingdom it was 80/100 000 and for the Indian subcontinent group born abroad it was $183 / 100000 .^{2}$

The changed total pattern (table 3 ) is entirely due to the reduced incidence in tuberculosis in the children from the Indian subcontinent, there being no significant change in any year, or group of years, in the white ethnic group. This does not mean that chemoprophylaxis is not effective in the white ethnic group, but that no general population benefit can be inferred from the data.

It has been shown therefore, that the introduction of prophylactic chemotherapy in the group from the Indian subcontinent has benefited individual subjects and the general population. Because the incidence figures of tuberculosis in children given by the 1978/9 Medical Research Council survey ${ }^{2}$ were annual, successful intervention with chemotherapy should have a cumulative effect: it should give benefit not just over the period of treatment, but also in subsequent years. In addition, as the number of children whose skin tests were strongly positive to tuberculin decreased over the period 1982-86 it implies that most of the reservoir of those at highest risk of developing tuberculosis had been given prophylactic treatment, which again has a cumulative effect on the pattern of the disease. The data in the group from the Indian subcontinent do show this trend, with no significant differences for the first year after the prophylaxis had started, but having an 
increasingly significant effect (with the exception of 1985 when two of the six cases were found on entry to the United Kingdom, and were thus not preventable by prophylaxis).

Although the Joint Tuberculosis Committee ${ }^{13}$ recommended isoniazid $10 \mathrm{mg} / \mathrm{kg}$ for six to 12 months for prophylaxis, Horne, in an editorial discussing the Joint Tuberculosis Committee recommendations, noted that, 'studies to assess the efficacy of shorter regimens containing rifampicin are in hand'. ${ }^{16}$ The six month regimen of rifampicin and isoniazid used from 1984-86 has also been used in some other areas with a high incidence of tuberculosis. It was successfully used in the Uppingham outbreak with no side effects reported. ${ }^{17}$ Because of the success reported here and the low rate of relapse with a shorter duration of treatment, the duration of chemotherapy was reduced to a total of four months from 1 January 1987.

The criteria for chemoprophylaxis introduced from late 1981 locally conform to the recommendations of the Joint Tuberculosis Committee. ${ }^{13}$ The introduction of chemoprophylaxis, although with a different drug regimen from that suggested by the Committee, has significantly reduced the incidence of tuberculosis in children from the Indian subcontinent. Chemoprophylaxis, therefore, has an important preventive role in the management of tuberculosis in areas with large immigrant populations. The combination of rifampicin and isoniazid may mean regimens lasting less than six months can be effective.

I would thank my colleagues Drs $\mathrm{N}$ Horsfield, S Jivani, C Fossard, and $\mathrm{J}$ Benson for their unstinting support for the programme; Mrs I Sawyer and Mrs D Duxbury for their clerical support; and Mrs J Garnett (Tuberculosis Nursing Officer) and her staff for their hard work in making the programme effective.

\section{References}

1 Gardner PA, Moss PD, Stalker R. Tuberculosis and the immigrant in Blackburn. Journal of Public Health 1972;86: 189-96.

2 Medical Research Council Tuberculosis and Chest Diseases Unit. A national survey of tuberculosis notifications in England and Wales. Br Med J 1980;281:895-8.

${ }^{3}$ Medical Research Council Tuberculosis and Chest Diseases Unit. National Survey of notifications of tuberculosis in England and Wales 1983. Br Med J 1985;291:658-61.

4 Joint Tuberculosis Committee of the British Thoracic and Tuberculosis Association. Chemoprophylaxis against tuberculosis in Britain. Tubercle 1973;54:309-15.

${ }^{5}$ Ferebee $\mathrm{SH}$. Controlled chemoprophylaxis trials in tuberculosis; a general review. Adv Tuberc Res 1969;17:28-104.

- Gryzbowski S, Ashley MJ, Pinkus G. Chemoprophylaxis in inactive tuberculosis: long term evaluations of a Canadian trial. Can Med Assoc J 1976;114:607-11.

${ }^{7}$ Horowitz O, Magnus K. Epidemiological evaluation of chemoprophylaxis against tuberculosis. Am J Epidemiol 1974;99: 333-42.

${ }^{8}$ Thompson NJ. Efficacy of various durations of isoniazid preventive therapy in tuberculosis: 5 years of follow-up in the IUAT trial. Bull WHO 1982:60:555-64.

${ }^{9}$ Ferebee SH, Mount FW, Anastasiades AA. Prophylactic effects of isoniazid on primary tuberculosis in children. A preliminary report. American Review of Tuberculosis and Pulmonary Diseases 1957;76:942-63.

10 Brunner DL, Comstock GW, Davey W, et al. Report of the Ad Hoc Committee on Isoniazid and Liver Disease. Am Rev Resp Dis 1971;104:454-9.

1 Ferebee SH. Long term effects of isoniazid prophylaxis. Bull Int Union Tuberc 1968;41:161-6.

12 Ormerod LP, Harrison JM, Wright PA. Drug resistance in Mycobacterium tuberculosis: a survey over 25 years in Blackburn. Thorax 1986;41:946-50.

13 Joint Tuberculosis Committee of the British Thoracic Society. Control and prevention of tuberculosis; a code of practice. $\mathrm{Br}$ Med J 1983;287:1118-21.

14 Anonymous. Isoniazid prevention of tuberculosis. [Editorial] Lancet 1983;i:395-6.

15 British Tuberculosis Association. A study of a standardised contact procedure in tuberculosis. Tubercle 1978;59:245-59.

${ }^{16}$ Horne NW. Control and prevention of tuberculosis; a code of practice. Thorax 1984:39:321-5.

17 Wales JM, Buchan AR, Cookson JB, Jones DA. Marshall BSM. Tuberculosis in a primary school: the Uppingham outbreak. $\mathrm{Br}$ Med J 1985;291:1039-40.

Correspondence to Dr LP Ormerod, Blackburn Royal Infirmary, Blackburn BB2 3LR.

Received 11 May 1987 